\title{
Formation of carbon nitride nanospheres by ion implantation
}

\author{
T. Thomé ${ }^{1}$, J. L. Colaux ${ }^{1}$, J. -F. Colomer ${ }^{2}$, G. Bertoni ${ }^{3}$, G. Terwagne ${ }^{1}$ \\ ${ }^{1}$ Laboratoire d'Analyses par Réactions Nucléaires, FUNDP, B-5000 Namur \\ ${ }^{2}$ Laboratoire de Résonance Magnétique Nucléaire, FUNDP, B-5000 Namur \\ ${ }^{3}$ EMAT, University of Antwerp, Groenenborgerlaan 171, B-2020, Antwerp
}

\begin{abstract}
Carbon nitride nanospheres have been synthesized into copper by simultaneous high fluence $\left(10^{18}\right.$ at.cm $\left.{ }^{-2}\right)$ implantations of ${ }^{12} \mathrm{C}$ and ${ }^{15} \mathrm{~N}$ ions. The composition of the implanted region has been measured using ${ }^{12} \mathrm{C}\left(\mathrm{d}, \mathrm{p}_{0}\right){ }^{13} \mathrm{C}$ and ${ }^{15} \mathrm{~N}\left(\mathrm{~d}, \mathrm{\alpha}_{0}\right){ }^{13} \mathrm{C}$ nuclear reactions induced by a 1.05 MeV deuteron beam. The ${ }^{12} \mathrm{C}$ and ${ }^{15} \mathrm{~N}$ depth profiles are very close and the retained doses into copper are relatively high, which indicates that carbon and nitrogen diffusion processes are likely limited during implantation. High resolution transmission electron microscopy (HRTEM) observations and electron diffraction (ED) analyses have been carried out to determine the structure of the nanospheres formed during implantation. Some consist in small hollow amorphous nanocapsules with sizes ranging from 30 to $100 \mathrm{~nm}$. Large gas bubbles with diameters up to $300 \mathrm{~nm}$ have also been observed in the copper matrix. Electron energy-loss spectroscopy (EELS) measurements performed on the small nanocapsules indicate that their shells are composed of carbon and nitrogen.
\end{abstract}

PACS codes : 25.45.De, 29.30.Ep, 68.37.Lp, 81.07.-b

Keywords : implantation, carbon nitride, NRA, TEM

Corresponding author: T. Thomé, FUNDP, 61 rue de Bruxelles, B-5000 Namur, Belgium E-mail : tristan.thome@fundp.ac.be - Phone : 32 (0) 81725477 


\section{Introduction}

In the last decade, the synthesis of carbon nitride structures has been extensively investigated due to their highly interesting physical properties such as high hardness and wear resistance. Indeed, some calculations predicted that several structures as $\alpha$ - and $\beta-C_{3} N_{4}$ would be harder than diamond [1]. However, even amorphous carbon nitride layers may have suitable physical properties for the use in many tribological applications, for instance as protective coatings. A wide variety of elaboration techniques have been used such as reactive sputtering, chemical vapour deposition, pyrolysis of organic materials, laser deposition and ion implantations [2-8]. So far, whatever the technique employed, mixed phase layers are quite often obtained and it remains very difficult to achieve fully crystalline phase formation. Among these techniques, ion implantation appears to be an interesting solution. It enables to modify near-surface properties of materials and allows a perfect control of the stoichiometry and thickness of modified layers by varying experimental implantation conditions as ion energy and fluence. Since successive carbon and nitrogen implantations in metals have not yet been conclusive [9], simultaneous implantations may be envisioned. Higher fluences could be attained and it would favor the interactions between carbon and nitrogen species during implantation.

In that work, we performed simultaneous implantations with carbon and nitrogen ions into copper samples using the non deviated beam line of a $2 \mathrm{MeV}$ Tandetron accelerator. Then, we determined the depth distributions of ${ }^{12} \mathrm{C}$ and ${ }^{15} \mathrm{~N}$ using ${ }^{12} \mathrm{C}\left(\mathrm{d}, \mathrm{p}_{0}\right){ }^{13} \mathrm{C}$ and ${ }^{15} \mathrm{~N}\left(\mathrm{~d}, \alpha_{0}\right){ }^{13} \mathrm{C}$ non resonant nuclear reactions induced by a $1.05 \mathrm{MeV}$ deuteron beam. Finally, we carried out HRTEM observations, ED analyses and EELS measurements to study the structure and the composition of the nano-objects formed during implantation.

\section{Experimental}


The samples are polished polycrystalline copper substrates. A simultaneous ${ }^{12} \mathrm{C}$ and ${ }^{15} \mathrm{~N}$ implantation was performed using the non deflected beam line of the $2 \mathrm{MV}$ ALTAÏS ${ }^{1}$ Tandetron accelerator installed at LARN. This implantation was carried out using a sputter ion source. A copper cathode filled with a mixture of $\mathrm{Ti}^{15} \mathrm{~N}$ and ${ }^{12} \mathrm{C}$ is bombarded with a $\mathrm{Cs}^{+}$ ion beam. The material is sputtered from the target and $\mathrm{CN}^{-}$anions are accelerated in the low energy part of the Tandetron acelerator. Passing through the stripper canal, the $\mathrm{CN}^{-}$anions are broken and a large variety of $\mathrm{C}^{\mathrm{n}+}$ and $\mathrm{N}^{\mathrm{q}+}$ cations are produced and accelerated in the high energy part of Tandetron accelerator towards the copper sample. The sample was maintained at room temperature and the vacuum pressure did not exceed $10^{-5} \mathrm{~Pa}$ during the implantation. The terminal voltage of the accelerator was fixed at $400 \mathrm{kV}$, which gives for instance energies of respectively $599 \mathrm{keV}$ and $648 \mathrm{keV}$ for ${ }^{12} \mathrm{C}^{+}$and ${ }^{15} \mathrm{~N}^{+}$ions (Table 1). The beam focalisation parameters were determined in order to favour the contribution of ${ }^{12} \mathrm{C}^{+}$and ${ }^{15} \mathrm{~N}^{+}$ions. The current density of the ion beam was measured around $20 \mu \mathrm{A} \cdot \mathrm{cm}^{-2}$ and the total fluence was about $10^{18}$ at.cm ${ }^{-2}$.

The depth distributions of carbon ${ }^{12} \mathrm{C}$ and nitrogen ${ }^{15} \mathrm{~N}$ in copper were studied using ${ }^{12} \mathrm{C}\left(\mathrm{d}, \mathrm{p}_{0}\right){ }^{13} \mathrm{C}$ and ${ }^{15} \mathrm{~N}\left(\mathrm{~d}, \alpha_{0}\right){ }^{13} \mathrm{C}$ non resonant nuclear reactions that make possible to depth profile ${ }^{12} \mathrm{C}$ and ${ }^{15} \mathrm{~N}$ atoms with a quite good resolution in a single and relatively rapid measurement. NRA experiments were performed with a $1.05 \mathrm{MeV}$ deuteron beam using the same facilities as for the implantation (ALTAÏS Tandetron accelerator). Two silicon surface barrier detectors were fixed at $150^{\circ}$ and $165^{\circ}$ relative to the incident beam to measure respectively NRA and RBS signals. A $12 \mu \mathrm{m}$ Mylar $^{\mathrm{TM}}$ absorber foil was placed in front of the NRA detector at $150^{\circ}$ in order to stop backscattered ions and to measure energetic $\alpha$ and proton particles. Since the cross section of the nuclear reaction on ${ }^{15} \mathrm{~N}$ is very low $\left(\sim 3 \mathrm{mb} . \mathrm{sr}^{-}\right.$ $\left.{ }^{1}\right)$, we used a large solid angle $(25.7 \mathrm{msr})$ for this detector to minimize the acquisition time

\footnotetext{
${ }^{1}$ Accélérateur Linéaire Tandetron pour l'Analyse et l'Implantation des Solides
} 
(about $20 \mathrm{~min})$. The RBS detector was collimated $(0.18 \mathrm{msr})$ to allow the detection of backscattered deuterons without any absorber foil. It was used as a monitor to determine the concentrations of nitrogen and carbon ions implanted in the copper sample from the estimated quantity of incident deuterons.

The carbon nitride structures formed during the ion implantation were characterized by HRTEM (JEM 4000EX and JEOL 200CX microscopes, working at 400 and $200 \mathrm{kV}$ respectively). EELS measurements have been performed on a Philips CM-30 - FEG microscope equipped with a post-column GIF200 system. The spectrum was recorded operating the microscope in the diffraction mode at an accelerating voltage of $300 \mathrm{kV}$ and with a spectrometer collection angle of $2.5 \mathrm{mrad}$. To achieve the plan view TEM analysis of the carbon nitride compounds synthesized into the bulk copper, the samples were electrolytically polished using appropriate chemical bathes (D2 from STRUERS, 6V) until a hole was formed in the substrate.

\section{Results and discussion}

Fig. 1 shows the experimental NRA spectrum measured at $150^{\circ}$. A very intense peak is observed just below $3 \mathrm{MeV}$, which can be attributed to the contribution of both surface contamination and implanted ${ }^{12} \mathrm{C}$ ions [10]. The peak detected around $4 \mathrm{MeV}$, corresponds to the ${ }^{15} \mathrm{~N}\left(\mathrm{~d}, \alpha_{0}\right){ }^{13} \mathrm{C}$ reaction with the implanted ${ }^{15} \mathrm{~N}$ ions. The total concentrations and the depth distributions of ${ }^{12} \mathrm{C}$ and ${ }^{15} \mathrm{~N}$ elements are determined from this spectrum using the SIMNRA program [11] in which specific nuclear reaction cross sections are considered and the copper sample is sliced into layers containing the elements concerned. The simulated SIMNRA spectrum is represented in solid line on Fig. 1 and the calculated depth profiles of ${ }^{12} \mathrm{C}$ and ${ }^{15} \mathrm{~N}$ are shown on Fig. 2. In the depth distribution of ${ }^{15} \mathrm{~N}$, several shoulders are observed around a main peak which can be attributed to ${ }^{15} \mathrm{~N}^{+}$implanted ions. Indeed, the energy of ${ }^{15} \mathrm{~N}^{+}$ions 
corresponds to an implantation projected range close to $580 \mathrm{~nm}$ in copper, according to SRIM2003 code calculations [12]. From the comparison with the SRIM2003 calculated projected ranges reported in the table 1, we can ascribe the first shoulder around $300 \mathrm{~nm}$ to neutral ${ }^{15} \mathrm{~N}$ implanted atoms and the 3 other ones at 880, 1020 and $1200 \mathrm{~nm}$ to respectively ${ }^{15} \mathrm{~N}^{2+},{ }^{15} \mathrm{~N}^{3+}$, and ${ }^{15} \mathrm{~N}^{4+}$ implanted ions. The quantity of nitrogen or carbon atoms retained in the copper matrix after the implantation, that corresponds to the total area under each depth profile, will be called retained dose hereafter. The maximal concentration and the retained dose for nitrogen species are respectively around 7 at. $\%$ and $4.5 \times 10^{17}$ at.cm ${ }^{-2} .{ }^{15} \mathrm{~N}$ surface peak is also detected, which can be explained by a slight diffusion process of nitrogen during the implantation.

In the ${ }^{12} \mathrm{C}$ depth profile, a shoulder ascribed to neutral ${ }^{12} \mathrm{C}$ implanted ions is detected before the main peak that corresponds to ${ }^{12} \mathrm{C}^{+}$ions. Nevertheless, only one is observed for deeper ranges, which indicates that almost no ${ }^{12} \mathrm{C}$ ions ionised more than 2 times are implanted into the sample. This was confirmed by measuring the different intensities of the multi-ionised carbon ion beams on a deviated beam line of the accelerator. A very thin ${ }^{12} \mathrm{C}$ contamination layer $(<1 \mathrm{~nm})$, characteristic of the carbon build-up phenomenon that occurs on surfaces during implantation, is detected [10]. This carbon layer is not visible in the Fig. 2 due to too small scales. The maximal concentration and the retained dose for carbon species are respectively around 8 at. $\%$ and $4.5 \times 10^{17}$ at. $\mathrm{cm}^{-2}$. We can notice that the entire carbon and nitrogen retained dose $\left(9 \times 10^{17}\right.$ at. $\left.\mathrm{cm}^{-2}\right)$ and the total dose generated by the implantation (around $10^{18}$ at.cm ${ }^{-2}$ ) are quite equal. That highlights the absence of a global and rapid release of carbon and nitrogen atoms outside the copper sample during implantation. Another feature to outline is that the nitrogen and carbon depth profiles are very close in shape and in intensity. This means that the diffusion processes of carbon and nitrogen atoms during 
implantation in copper are likely limited. This strong correlation also strengthens the assumption that carbon nitride compounds may be synthesized by implantation into copper.

Typical plane view TEM observations performed after implantation are shown in Fig. 3 and 4. They reveal the presence of several nano-objects, with diameters ranging from 30 to $300 \mathrm{~nm}$ and a well-defined spherical shape, embedded in a dominant copper crystalline matrix. The nano-compounds with a diameter larger than $50 \mathrm{~nm}$ (Fig. 3) may be large gas bubbles whereas the other ones (Fig. 3 and 4) are small hollow nanospheres probably composed with carbon and nitrogen as suggested by the NRA results presented above. Besides, XPS measurements performed in another study on copper substrates implanted in similar conditions showed the formation of characteristic types of chemical bonds between carbon and nitrogen [13]. A close up HRTEM image of a small empty nanocapsule and its associated selected area electron diffraction (SAED) pattern are presented in Fig. 5. It clearly indicates that the hollow spherical shells formed during implantation are amorphous. Indeed, several diffuse rings indicating the amorphous structure can be observed in the SAED pattern (inset of Fig. 5). From the EELS spectrum in Fig. 6, we deduced the composition of these empty nanospheres to be carbon nitride. Indeed, the spectrum presents $\mathrm{C}$ and $\mathrm{N} K$ edges, with additional peaks attributed to $\mathrm{O}(\mathrm{O} K$ edge) coming from contamination (oxidation) of nanospheres, and to $\mathrm{Cu}(\mathrm{Cu} K$ edge, not shown) coming from the substrate. The spectrum obtained is very similar to the ones presented in [14] for carbon nitride thin films with high nitrogen content. Indeed, the relative quantification indicates a nitrogen percent content of about $26 \%$.

The presence of empty nanospheres is an interesting result that has also been reported by Abe and Cabioc'h [15-17] for single carbon ion implantations into copper substrates. These previous investigations demonstrated that the presence of these sorts of empty nanocapsules was due to a carbon precipitation at copper grain boundaries. Surprisingly, they 
observed in-situ that the so-encapsulated copper nanograins disappeared progressively by a copper diffusion through the defective carbon layers. Such a behavior can also explain the formation of the nanocapsules observed in our substrates. The presence of amorphous carbon parts around the nanocapsules can be attributed to a carbon precipitation at the surface and along boundaries of large copper grains. These results indicate that simultaneous implantations of carbon and nitrogen can be used to produce carbon nitride compounds such as nanospheres.

\section{Conclusion}

The depth distributions of carbon ${ }^{12} \mathrm{C}$ and nitrogen ${ }^{15} \mathrm{~N}$ co-implanted in a copper sample have been determined using ${ }^{12} \mathrm{C}\left(\mathrm{d}, \mathrm{p}_{0}\right){ }^{13} \mathrm{C}$ and ${ }^{15} \mathrm{~N}\left(\mathrm{~d}, \mathrm{\alpha}_{0}\right){ }^{13} \mathrm{C}$ non resonant nuclear reactions induced by a $1.05 \mathrm{MeV}$ deuteron beam. We are able to distinguish the different contributions of each ionised element (at least to 4 times for nitrogen while no more than 2 times for carbon) to the total nitrogen and carbon depth distributions. The relatively high carbon and nitrogen doses retained in the bulk and the strong correlation between nitrogen and carbon depth profiles indicate that the carbon and nitrogen diffusion processes are limited during implantation and that carbon nitride compounds are likely synthesized in the bulk of copper.

High resolution transmission electron microscopy (HRTEM) observations indicate that at least two kinds of nano-compounds are formed in the copper matrix during implantation : large gas bubbles and small nanospheres. The sizes of these nano-objects range from 30 to $300 \mathrm{~nm}$ and most of them have a well defined spherical shape. Electron diffraction analyses and EELS measurements show that the nanospheres are hollow amorphous nanocapsules composed of carbon and nitrogen. This study suggests that carbon and nitrogen coimplantation is an interesting technique to produce carbon nitride compounds. 


\section{Acknowledgments}

The authors thank Prof. G. Van Tendeloo for the use of microscopes of EMAT laboratory (University of Antwerp). The authors are grateful to the Belgian Interuniversity Research Project on Quantum Size Effects in Nanostructured Materials (PAI/IUAP P5/01). J.F. C. was supported as postdoctoral fellow by the Belgian National Fund for Scientific Research (FNRS).

\section{References}

[1] A. Lui, M. Cohen, Science 247 (1989) 688

[2] K.M. Yu, M.L. Cohen, B.E. Haller, W.L. Hansen, A.Y. Liu, J.C. Wu, Phys. Rev. B, 49 (1994) 5034

[3] L. Maya, D.R. Cole, E.W. Hagaman, J. Am. Ceram. Soc. 74 (1991) 1686

[4] C. Niu, Y.Z. Lu, C.M. Lieber, Science 261 (1993) 334

[5] E. Gyorgy, V. Nelea, I. Mihailescu, A. Perrone, H. Pelletier, A. Cornet, S. Ganatsios, J. Werckmann, Thin Solid Films, 388 (2001) 93

[6] A. Hoffman, I. Gouzman and R. Brener. Appl. Phys. Lett. 64 (1994), p. 845

[7] E. Romanowsky, O. Bespalova, A. Borisov, N. Goryaga, V. Kulikauskas, V. Sukharev, V. Satekin, Nucl. Instr. Meth. B, 139 (1998) 355

[8] N. Hellgren, M.P. Johansson, E. Broitman, L. Hultman and J.-E. Sundgren. Phys. Rev., B 59 (1999), 5162

[9] R. Sanchez, J. A. Garcia, A. Medrano, M. Rico, R. Martinez, R. Rodriguez, C. FernandezRamos, A. Fernandez, Surface and Coatings Technology 158-159 (2002) 630

[10] J. Colaux, G. Terwagne, Nucl. Instr. Meth. B 240 (2005) 429 
[11] M. Mayer, SIMNRA, a Simulation Program for the Analysis of NRA, RBS and ERDA, Proc. $15^{\text {th }}$ Int. Conf. Appl. Accelerators in Research and Industry, J. L. Duggan and I. L. Morgan (eds.), AIP Conf. Proc. 475 (1999) 541

[12] J.F. Ziegler, J.P. Biersack, U. Littmark, The Stopping and Range of Ions in Solids, Pergamon, New York, 1967

[13] T. Thome, J. Colaux, G. Terwagne, J. Elec. Spec. Rel. Phen. 151 (2006) 19

[14] A. Fernandez, P. Prieto, C. Quiros, J. M. Sanz, J-M. Martin, and B.Vacher, Appl. Phys. Lett., 69 (6) (1996) 764

[15] H. Abe, Diamond Rel. Mat., 10 (2001) 1201

[16] E. Thune, T. Cabioc'h, P. Guerin, M. F. Denanot, M. Jaouen, Mat. Letters, 54 (2002) 222

[17] E. Thune, T. Cabioc’h, M. Jaouen, F. Bodart, Phys. Rev. B, 68 (2003) 115434 


\section{Tables}

Table 1: Energies and calculated $\left(\mathrm{R}_{\mathrm{SRIM}}\right)$ and experimental $\left(\mathrm{R}_{\mathrm{exp}}\right)$ projected ranges of ${ }^{12} \mathrm{C}^{\mathrm{p}+}$ and ${ }^{15} \mathrm{~N}^{\mathrm{q}+}$ ions implanted into copper with a terminal voltage of $400 \mathrm{kV}$ on our Tandetron accelerator.

\begin{tabular}{|c|c|c|c|}
\cline { 2 - 4 } \multicolumn{1}{c|}{} & $\mathrm{E}(\mathrm{keV})$ & $\mathrm{R}_{\text {SRIM }}(\mathrm{nm})$ & $\mathrm{R}_{\exp }(\mathrm{nm})$ \\
\hline${ }^{12} \mathrm{C}$ & 195 & 240 & 300 \\
\hline${ }^{12} \mathrm{C}^{+}$ & 599 & 585 & 600 \\
\hline${ }^{12} \mathrm{C}^{2+}$ & 1002 & 840 & 880 \\
\hline${ }^{15} \mathrm{~N}$ & 244 & 250 & 300 \\
\hline${ }^{15} \mathrm{~N}^{+}$ & 648 & 580 & 600 \\
\hline${ }^{15} \mathrm{~N}^{2+}$ & 1051 & 820 & 880 \\
\hline${ }^{15} \mathrm{~N}^{3+}$ & 1455 & 1000 & 1020 \\
\hline${ }^{15} \mathrm{~N}^{4+}$ & 1858 & 1180 & 1220 \\
\hline
\end{tabular}




\section{Figure captions}

Figure 1: Experimental (dots) and simulated (solid lines) NRA spectra at $150^{\circ}$ of the ${ }^{12} \mathrm{C}$ and ${ }^{15} \mathrm{~N}$ co-implanted copper sample (integrated charge $=150 \mu \mathrm{C}$ ).

Figure 2: Depth distributions of ${ }^{12} \mathrm{C}$ (filled triangles) and ${ }^{15} \mathrm{~N}$ (open squares) ions determined from SIMNRA simulations for the ${ }^{12} \mathrm{C}$ and ${ }^{15} \mathrm{~N}$ co-implanted copper sample. Arrows indicate the calculated projected ranges $\left(\mathrm{R}_{\mathrm{SRIM}}\right)$ of ${ }^{12} \mathrm{C}^{\mathrm{p}+}$ and ${ }^{15} \mathrm{~N}^{\mathrm{q}+}$ ions.

Figure 3: TEM image of large gas bubbles in the copper substrate.

Figure 4: TEM image of small carbon nitride hollow nanospheres in the copper substrate.

Figure 5: TEM image of an isolated carbon nitride nanosphere with its associated selected electron diffraction pattern (in the inset).

Figure 6: EELS spectrum of an isolated carbon nitride nanosphere with in the insets the enlarged views of C $K$ edge (a) and N $K$ edge (b), respectively. 


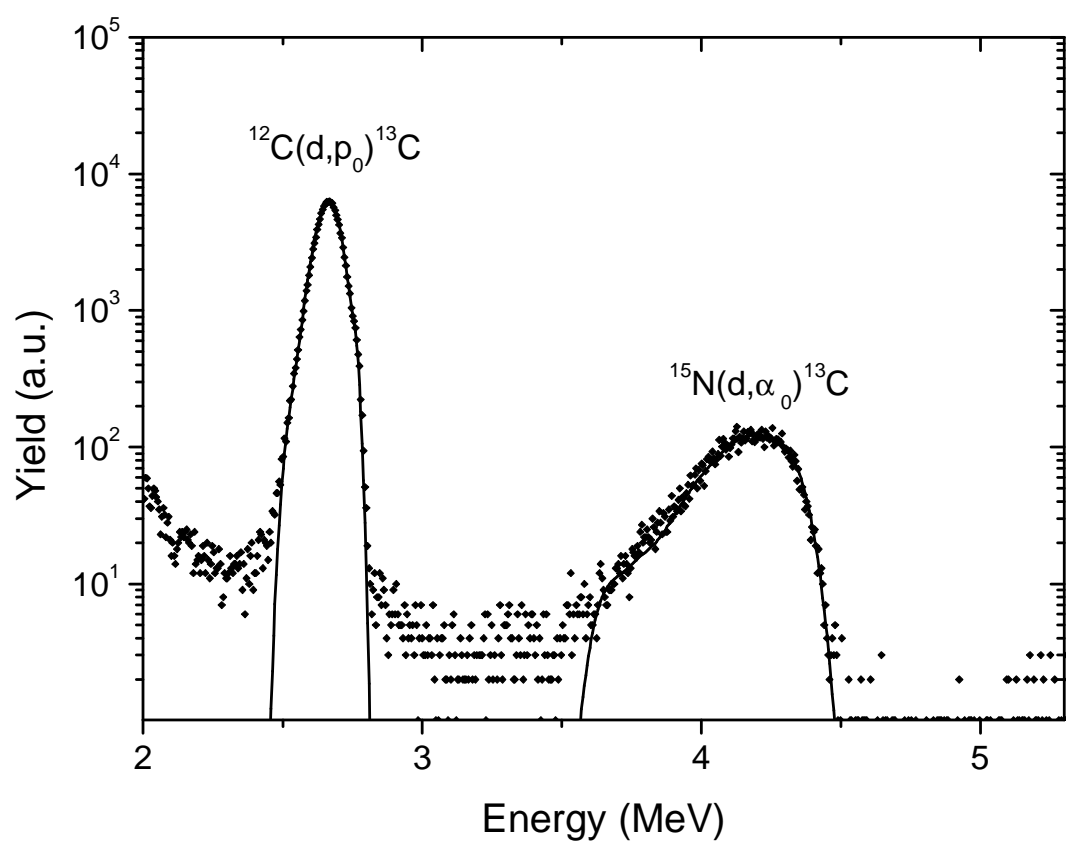

Figure 1 


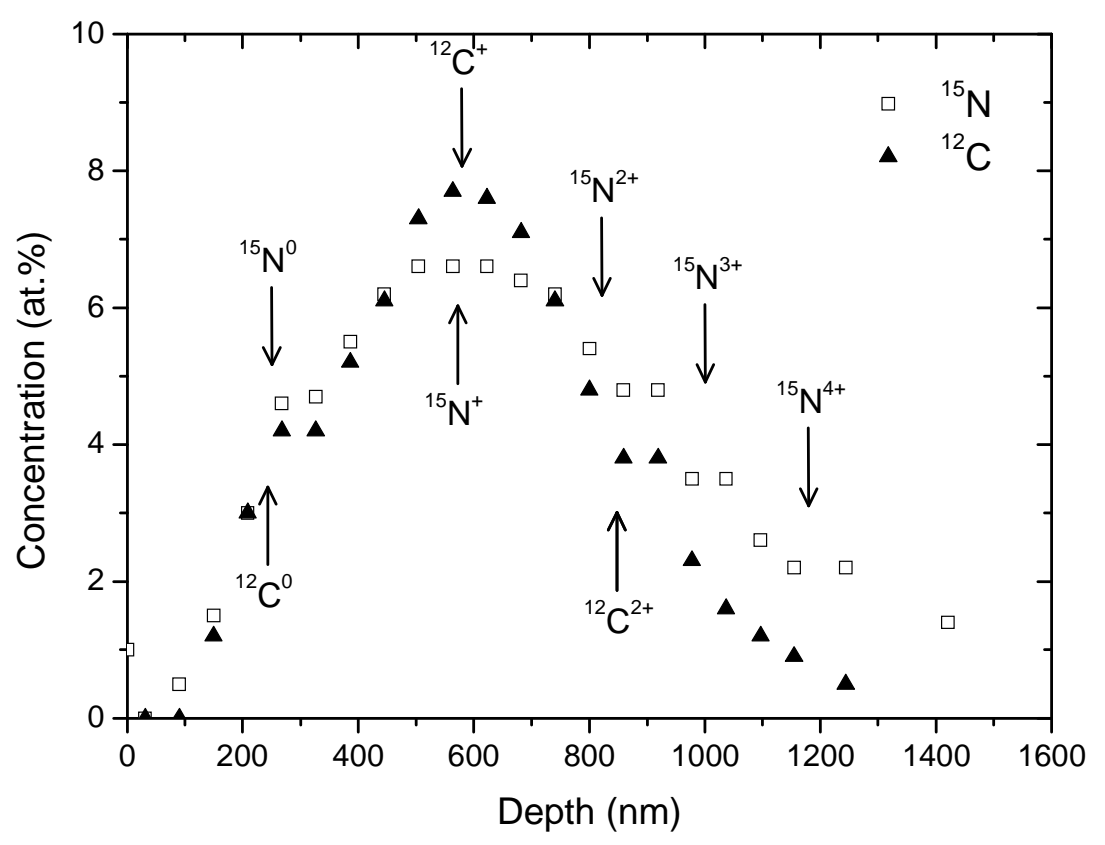

Figure 2 


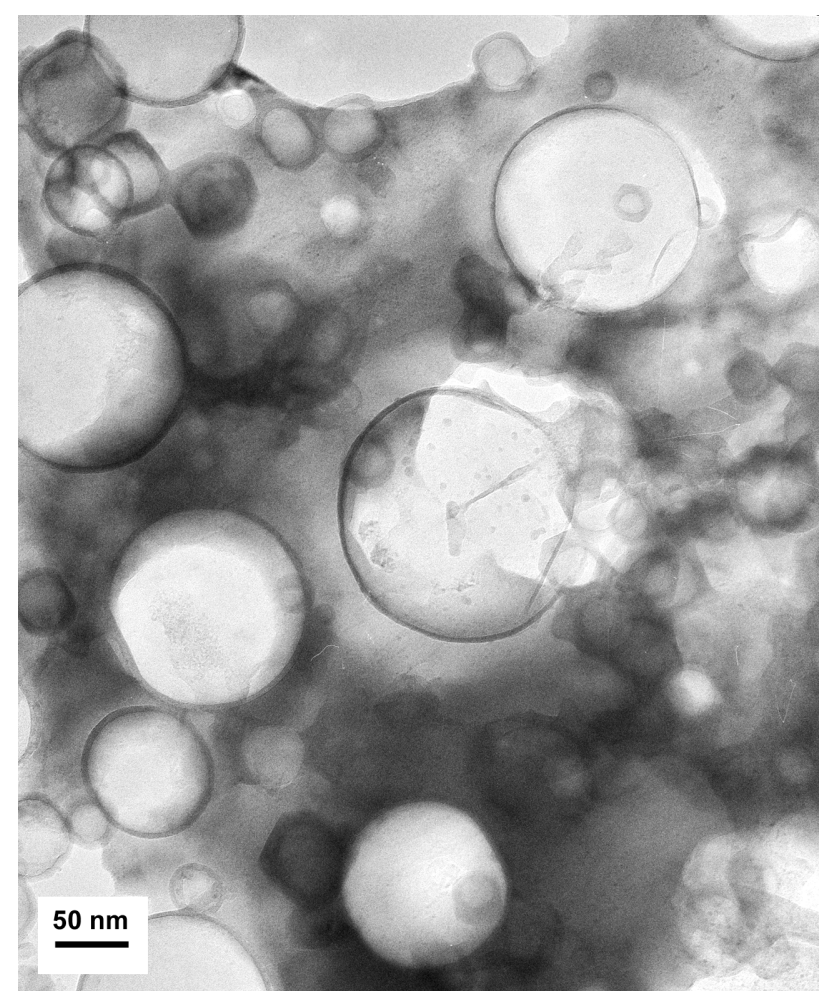

Figure 3 


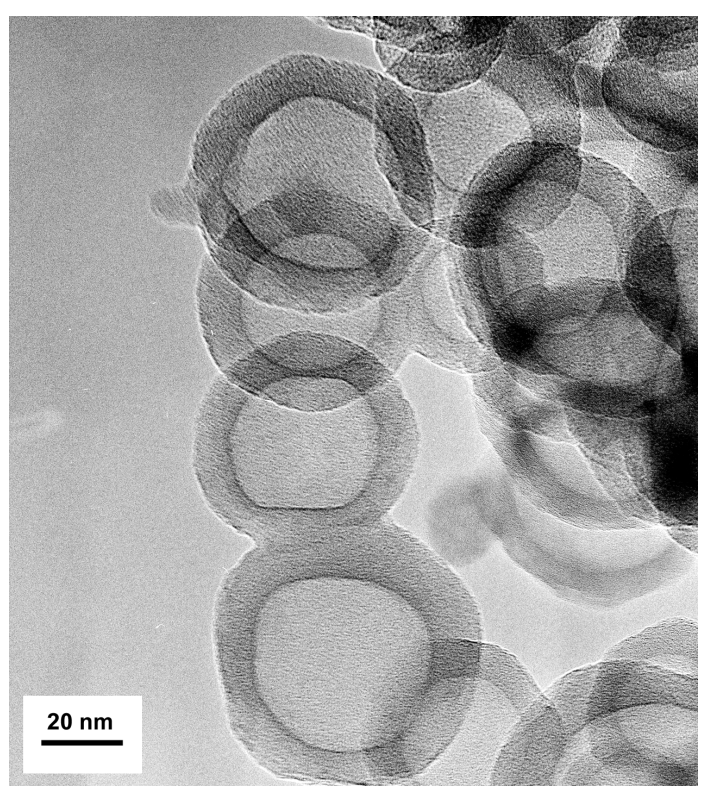

Figure 4 


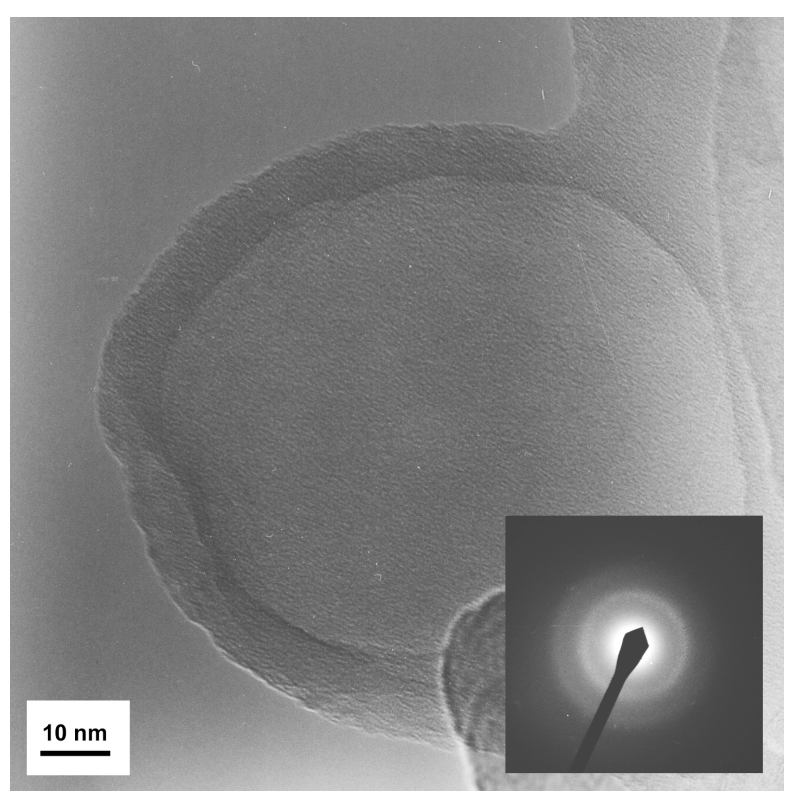

Figure 5 


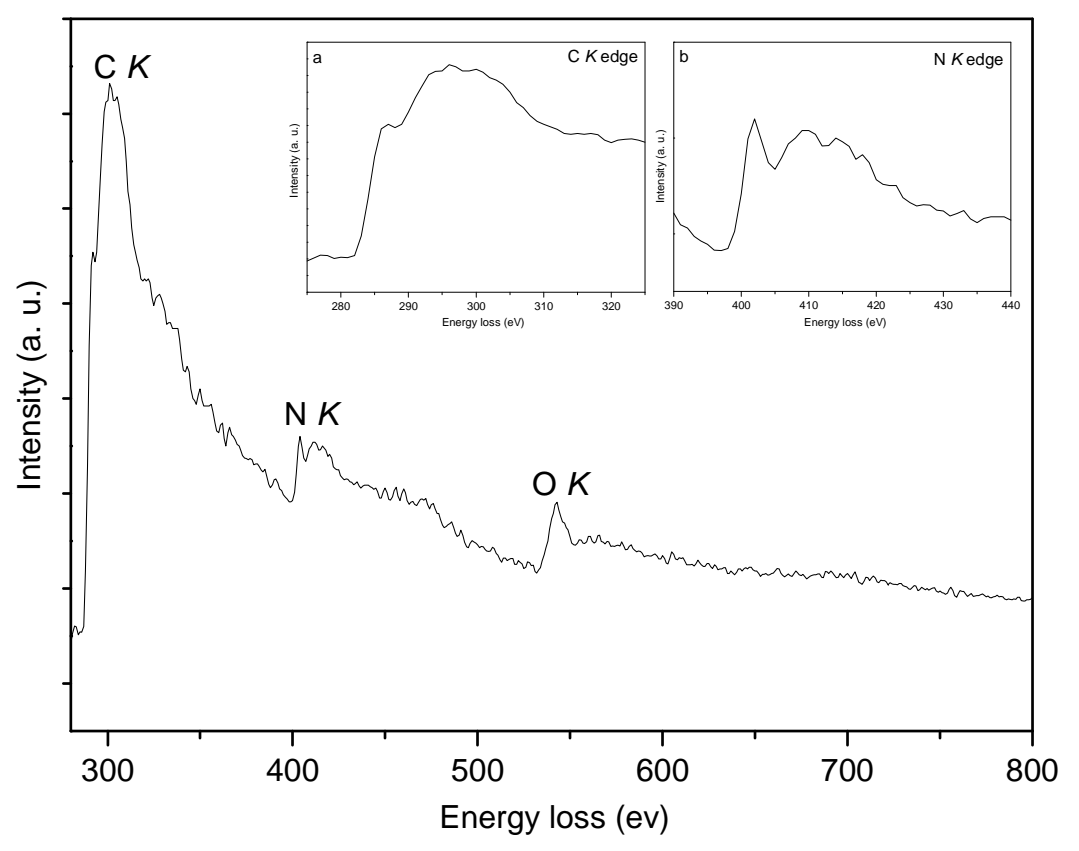

Figure 6 